\title{
Lanthanum Carbonate
}

National Cancer Institute

\section{Source}

National Cancer Institute. Lanthanum Carbonate. NCI Thesaurus. Code C61801.

The carbonate salt of lanthanum, a silvery white metallic element of the lanthanoids family, with phosphate binding property. Lanthanum carbonate dissociates in gastric acid to release lanthanum ions, which then binds dietary phosphate. This agent inhibits the absorption of phosphate by forming highly insoluble lanthanum-phosphate complexes that reduce concentrations of serum phosphate and calcium phosphate. 